\title{
Strong correlation between the complement-mediated antibody-dependent enhancement of HIV-1 infection and plasma viral load
}

\author{
Judit Szabóa , Zoltán Prohászkab , Ferenc D. Tóth ${ }^{a}$, Ágnes Gyuris ${ }^{c}$, \\ Judit Segesdi ${ }^{\mathrm{c}}$, Dénes Bánhegyi ${ }^{\mathrm{d}}$, Eszter Ujhelyi ${ }^{\mathrm{e}}$, János Minárovits ${ }^{\mathrm{c}}$ \\ and George Füst ${ }^{b}$
}

\begin{abstract}
Objective: We have previously demonstrated that complement-mediated antibodydependent enhancement (C-ADE) of HIV-1 infection correlates with accelerated immunosuppression and disease progression in HIV-1-infected individuals. In the present work the relationship between C-ADE and plasma HIV-1 RNA concentrations was studied to determine the effect of C-ADE on viral replication.

Methods: Three studies were performed: (a) C-ADE and HIV-1 RNA concentrations were determined in the serum and plasma aliquots taken at the same time from 98 HIV patients, mostly in the advanced stage of the disease; (b) the above two parameters as well as HIV enzyme-linked immunosorbent assay (ELISA)-reactive antibodies (Abbott HIV 1/2 test), and p24 antigen levels (Abbott antigen test; Abbott, Delkenheim, Germany) were determined in four seroconversion panels purchased from the Boston Biomedica firm; (c) changes of HIV-1 RNA concentration and C-ADE during a 17 month follow-up period were determined in 18 HIV-infected patients. C-ADE was measured by the method previously established in our laboratories. The results were expressed by an enhancement/neutralization index (E/NI). HIV-1 RNA levels were determined with the Amplicor monitor kit (Roche, Basel, Switzerland), and in some experiments with the nucleic acid sequence based amplification (Organon Teknika, Turnhout, Belgium) kits.
\end{abstract}

Results: (a) We found a highly significant $(P<0.0001)$ positive correlation between $\mathrm{E} / \mathrm{NI}$ values reflecting the extent of HIV-1 infection enhancement and plasma HIV-1 RNA levels. Both E/NI and HIV-1 RNA levels negatively correlated to the CD4 cell counts. (b) C-ADE was first detected just before, or concomitantly with, seroconversion in 4/4 seroconversion panels. (c) Both $\mathrm{E} / \mathrm{NI}$ values and HIV-1 RNA levels significantly $(P<0.001)$ increased during a 17 month observation period in 18 HIV-infected patients.

Conclusion: We found strong association between the extent of the complementmediated antibody-dependent enhancement of HIV-1 infection and the plasma viral load in HIV patients. On the basis of these findings, C-ADE correlates with HIV replication in vivo, and potentially contributes to the progression of HIV disease.

(C) 1999 Lippincott Williams \& Wilkins

AIDS 1999, 13:1841-1849

Keywords: HIV-1, AIDS enhancing antibodies, complement, viral load, C-ADE

From the ${ }^{\mathrm{a}}$ Institute of Microbiology, University Medical School, Debrecen, Hungary; ${ }^{\mathrm{b}}$ Third Department of Medicine, Semmelweis Medical University, and Research Group of Metabolism, Genetics and Immunology, Hungarian Academy of Sciences, Budapest, Hungary; ${ }^{C}$ Research Group of Microbiology, National Center of Epidemiology, Budapest, Hungary; ${ }^{\mathrm{d}}$ Department of Immunology, St László Hospital, Budapest, Hungary; and 'National Blood Transfusion Center, Budapest, Hungary.

Sponsorship: This study was supported by the PECO'94 grant to the European Union Concerted Action 'Development and Evaluation of Immunological and Virological Progression Markers to be used for Monitoring of Therapy of HIV Infection' and by the research grants of the Hungarian National AIDS Committee. This work was performed in the framework of EU Concerted Action 'The role of complement in the susceptibility to infections and chronic diseases' and also supported financially by the EU-98-D9-124 (National Committee for Technological Development of Hungary).

Correspondence to Dr George Füst, Third Department of Medicine, Semmelweis Medical University, H-1125 Budapest, Kútvölgyi Street 4, Hungary.

Tel/fax: + 361-212-9351.

Received: 15 December 1998; revised: 25 May 1999; accepted: 15 June 1999. 


\section{Introduction}

At all stages of disease, HIV-1 RNA plasma levels, a measure of the plasma viral load, remains the most potent predictor of outcome in HIV-infected individuals [1-5]. Primary HIV infection is characterized by a high titre viraemia; plasma HIV RNA concentrations can exceed $10^{6}-10^{7}$ copies $/ \mathrm{ml}$ [6]. In concert with seroconversion, initial symptoms resolve, viral load falls precipitously by 2 or 3 logs, and follicular dendritic cells (FDC) trap HIV as antigen-antibody-complement complexes in the lymphoid tissue [7]. After fluctuating for approximately 6 months, the plasma HIV RNA level appears to stabilize at a steady state or 'set-point' [1].

The dominant host immunological factors involved in the clearance of viraemia after its initial burst and factors that govern viral load during the later stages of HIV disease have not been completely elucidated. The relationship between humoral immune response, viral load and progression to AIDS remains uncertain [8]. According to recent studies, the levels of both autologous and heterologous neutralizing antibodies are low or absent early in HIV infection without apparent correlation to the decline in viraemia [9-12], although some exceptions were reported [13,14]. Usually the appearance of neutralizing antibodies is delayed 2-3 months when compared with the clearance of the acute viraemic phase [12]. No convincing relationship between neutralizing antibodies and containment of the viral load in the chronic phase of HIV infection [15] or association with long-term non-progression has been noted $[12,16]$.

By contrast, several recent data indicate that cytotoxic T lymphocytes (CTL) contribute to the immunological control of virus replication [11,17-19]. In addition to the CTL response, CD8 $\mathrm{T}$ cell-mediated noncytotoxic suppression of HIV replication also significantly contributes to the control of viraemia and disease progression in adults and infants [20,21]. The vigorous cell-mediated immune responses against HIV are thus considered to be important in reducing viral load. The continued presence of HIV in the plasma and lymph nodes, however, shows that host immunity is incomplete. During clinical latency, HIV accumulates in the lymphoid organs and replicates actively, a mechanism responsible for the progressive disorganization and destruction of secondary lymphoid organs, ultimately resulting in the progression of disease. Presently, the identification of the factors that lead to disease progression is a matter of debate.

Previous studies [22-25] demonstrated the presence of enhancing antibodies (antibodies that facilitate HIV infection in vitro) in the blood of HIV-infected individuals. Two types of enhancing antibodies were described: complement-independent, Fc-receptor dependent [22], and complement-mediated antibodies [23-25]. The HIV infection-facilitating effect of the latter type of antibodies is mediated by the activation of a plasma enzyme system, the complement system, and mainly by complement receptor type 2 (CR2) on the surface of target cells [25].

Some data confirm the clinical relevance of the enhancing antibodies in HIV infection. Homsy et al. [26] found the appearance of the Fc-receptor dependent enhancing antibodies to be associated with the progression of HIV disease. According to our previous studies, complement-mediated antibody-dependent enhancement (C-ADE) may also be of clinical importance. We have measured C-ADE with a markedly higher frequency and in higher amounts in the sera of patients with advanced stage HIV disease compared with those in the sera of asymptomatic HIV-infected persons [27]. These findings were recently confirmed by McDougall et al. [28]. In a more recent study [29], we have demonstrated the appearance of high-titre $\mathrm{C}-\mathrm{ADE}$ to predict the rapid decline of the CD4 cell counts and an increased probability of the development of AIDS. In the same study, the lack of neutralization measured in the presence of complement was also found to be associated with a more rapid clinical progression of HIV disease, whereas no such association was observed when the same measurement was performed using heat-treated serum samples without the addition of complement.

These findings prompted us to study the possible relationship between the titre of C-ADE and viral load, the best predictive marker of HIV disease progression.

\section{Materials and methods}

\section{Patients and sera}

Ninety-eight patients [87 men, 11 women, 38 (range 10-68) years old] in advanced stages of HIV disease [58 patients in Centers for Disease Control and Prevention (CDC) stage III or IVA, 40 patients in CDC stage IVB or IVC] were enrolled in a cross-sectional study. The average CD4 cell counts of the patients was $261 \pm 181$ cells $/ \mu \mathrm{l}$ (mean $\pm \mathrm{SD}$ ), and the CD4 cell counts of 80 out of $98(82 \%)$ of the patients were below 400 cells $/ \mu 1$.

A longitudinal study of C-ADE and viral load was performed in 18 patients in advanced stage HIV disease untreated $(\mathrm{n}=7)$, or treated with two different antiviral protocols $(\mathrm{n}=11$, zidovudine monotherapy: six, zidovudine plus didanosine plus zalcitabine: five). The patients were followed-up for a median of 17 (range 6-26) months. The baseline CD4 cell count of the patients was $333 \pm 201$ cells $/ \mu 1$. 
The appearance of enhancing antibodies shortly after HIV infection was studied by using seroconversion panels of Boston Biomedica Inc. (West Bridgewater, MA, USA). Four panels (D, J, P, and Y) were purchased from the firm. Each seroconversion panel consists of undiluted, frozen aliquots of plasma units collected from a single donor. The samples do not contain preservatives. Before study, plasma samples were recalcified, centrifuged and the supernatants were heat treated $\left(56^{\circ} \mathrm{C}, 30 \mathrm{~min}\right)$.

\section{Cells and virus}

HIV-1 $1_{\text {IIIB }}$-producing $\mathrm{H} 9$ cells as well as MT-4 target cells were maintained in RPMI 1640 medium containing $15 \%$ heat inactivated fetal calf serum and $50 \mu \mathrm{g}$ gentamicin $/ \mathrm{ml}$ of cell culture medium. The virus titre was determined by end-point dilution on $\mathrm{H} 9$ cells and defined as the $50 \%$ tissue culture infective dose on MT-4 cells (TCID 50 value).

\section{Measurement of enhancement/neutralization of in-vitro HIV infection in the presence and absence of complement}

The assay was carried out as described previously [27]. Briefly, serum samples from the patients were heattreated $\left(56^{\circ} \mathrm{C}, 30 \mathrm{~min}\right)$ and diluted at $1: 64$ in culture medium in triplicate. One hundred microlitres of antibody dilutions were mixed with $100 \mu$ l of pooled sera from HIV-seronegative healthy persons (normal human serum; NHS). HIV-1 ${ }_{\text {IIIв }}\left(100\right.$ TCID $\left._{50}\right)$ in $100 \mu \mathrm{l}$ culture medium was added to $100 \mathrm{ml}$ of antibody dilutions and incubated at $37^{\circ} \mathrm{C}$ for $1 \mathrm{~h}$. The final concentration of human complement in the samples added to target cells was thus $1: 4$. In the case of each patient's serum, sample mixtures without complement in which NHS was replaced by culture medium were also tested. In each series of experiments, control cultures infected with the virus alone were also established. Then, $5 \times 10^{5}$ MT-4 cells in growth medium were added and incubated in this medium without change for 5 days at $37^{\circ} \mathrm{C}$. The growth of HIV in the cultures was monitored on each day by the reverse transcriptase (RT) assay, as outlined by Hoffman et al. [30]. Peak RT values were observed almost exclusively at day 5. The results were measured as c.p.m. and expressed finally by an index (enhancement/neutralization index; E/NI) value. Index values were calculated as follows: means of triplicate peak RT (c.p.m.) values measured in cultures infected with the mixtures of virus, patient's serum (and NHS) at day 5 were divided by the means of triplicate peak c.p.m. values measured in control cultures infected with virus alone at day 5 . Samples with an E/NI of less than 0.5 (twofold decrease in virus production) were considered as neutralizing, whereas samples with an E/NI exceeding 2.0 (twofold increase in virus production) were considered as enhancing. The variation coefficient of the method was $7.23 \%$.

\section{Determination of CD4 cell counts}

$\mathrm{T}$ cell subset determinations were performed by flow cytometry (FACScan) by using the IMK lymphocyte kit (Becton Dickinson, Mountain View, CA, USA).

\section{Measurement of HIV-1 RNA level in the plasma samples of the patients}

In the cross-sectional study, plasma HIV-1 RNA concentrations were determined by the Amplicor monitor test (Roche, Basel, Switzerland) or by the NASBA method (Organon Teknika, Turnhout, Belgium),
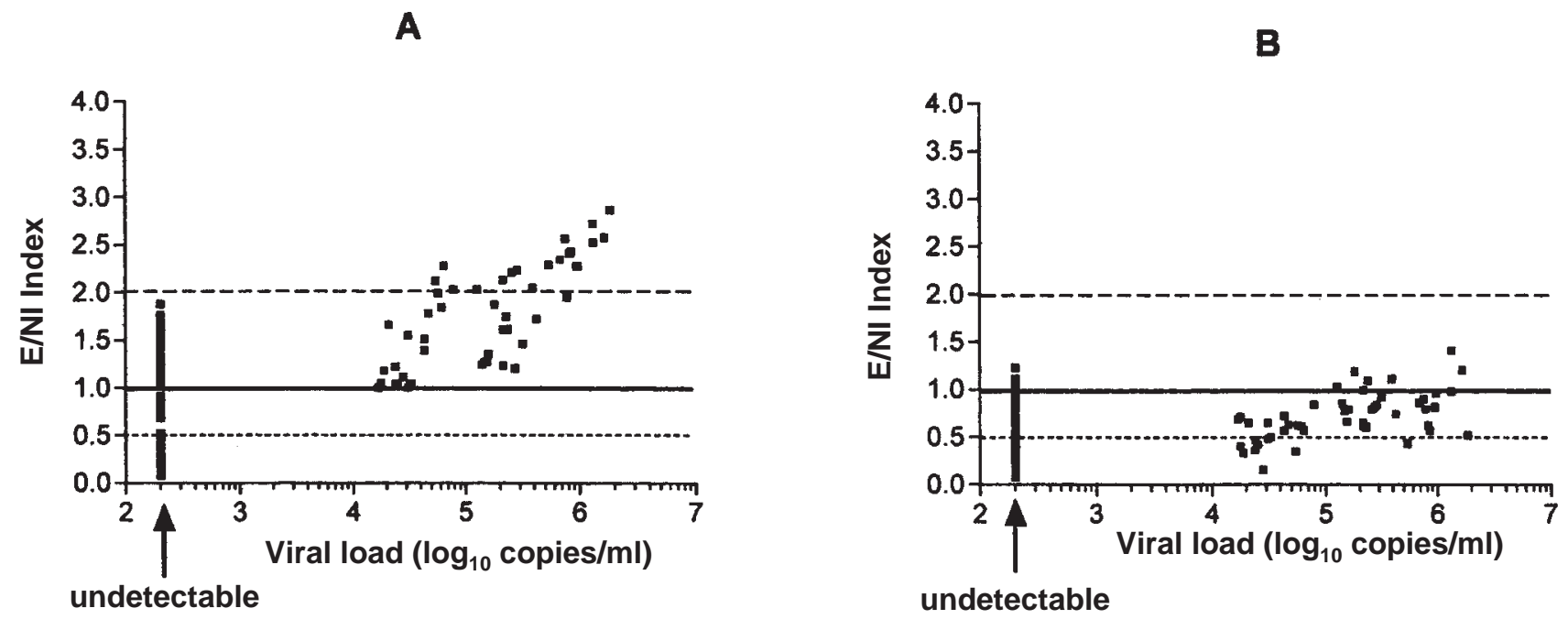

Fig. 1. Correlation between the plasma HIV-1 RNA concentration detected by the Amplicor assay and the enhancement/ neutralization index (E/NI) measured in MT-4 cell cultures infected with mixtures of HIV-1 $1_{\text {IIIB }} 1: 64$ dilutions of heat-treated serum samples with (A) or without (B) pooled serum from HIV seronegative subjects as complement source in 98 HIV-infected subjects. Values above the dashed line indicate enhancement whereas those below the dotted line indicate neutralization. Spearman correlation coefficient $(P$ value) for A: $0.709(<0.0001)$ for B: $0.276(0.0059)$. 
Table 1. Correlation of virus neutralization in the presence or absence of complement with plasma HIV-1 RNA (Amplicor)

\begin{tabular}{|c|c|c|}
\hline & No. of patients tested & $\begin{array}{l}\text { HIV-1 RNA, copies/ml, median } \\
\text { (25-75th percentile) }\end{array}$ \\
\hline $\mathrm{E} / \mathrm{NI}<0.5$ (neutralization) both in the presence and absence of complement & 12 & $200(200-200)$ \\
\hline $\mathrm{E} / \mathrm{NI}<0.5$ (neutralization) only in the absence of complement & 17 & $19000(200-25000)$ \\
\hline No neutralization in either the absence or presence of complement & 69 & $43000(200-226000)$ \\
\hline Kruskal-Wallis test ( $P$ value) & & 0.0014 \\
\hline
\end{tabular}

$\mathrm{E} / \mathrm{NI}$, enhancement/neutralization index.

whereas in the other two studies only the Amplicor assay was used. Both assays were used according to the manufacturer's instructions.

\section{Results}

\section{Correlation between complement-mediated antibody-dependent enhancement and HIV-1 RNA concentrations}

C-ADE and HIV-1 RNA concentrations were determined in the serum and plasma samples, respectively, taken at the same time from 98 patients. A strong positive correlation was found between viral load and E/NI measured in MT-4 cell cultures infected with complement-containing mixtures (Fig. 1A), whereas in cultures with no complement added a much weaker but still significant positive correlation was obtained (Fig. 1B). A similar correlation was found between viral load measured with the NASBA method and E/NI values $(R=0.627, P<0.0001$, and $R=0.207, P$ $=0.041$, respectively, data not shown).

When E/NI values measured in sera from patients with detectable and undetectable HIV-1 RNA were compared, E/NI values measured in cultures infected in the presence of complement were significantly $(P<0.0001$, Mann-Whitney test) higher in the sera from patients with detectable [1.75 (1.24-2.21), median (25-75th percentile)] than in those with undetectable viral load [1.02 (0.46-1.43)]. In contrast, there were no significant $(P=0.109)$ differences between the same groups in $\mathrm{E} / \mathrm{NI}$ values measured in cultures infected without complement $[0.69(0.57-0.81)$ and $0.60(0.29-0.86)$, respectively].

Next, the patients were divided according to the E/NI values measured in cultures infected in the presence and absence of complement (Table 1). No HIV-1 RNA could be detected in plasma samples of patients whose sera neutralized HIV-1 not only in the absence but also in the presence of complement. Viral load was markedly higher in patients whose serum samples neutralized HIV-1 only in the absence of complement, whereas the highest HIV-1 RNA concentrations were measured in the group of patients whose sera did not neutralize HIV infection even in the presence of complement. According to the Kruskal-Wallis test, there was a highly significant $(P=0.0014)$ difference among the three groups of the patients.

In the 98 patients tested, CD4 cell counts inversely correlated to the E/NI values measured in cultures infected in the presence of complement (Fig. 2). In addition, E/NI values measured in the presence of complement were significantly $(P=0.02)$ higher in the AIDS patients than in patients in a less advanced (CDC stage III or IVA) stage of HIV disease (data not shown).

In control experiments, serum samples from 48 HIVnegative persons were tested. No neutralizing or enhancing activities were found either in the presence or absence of complement in these sera (data not shown).

\section{Early appearance of complement-mediated antibody-dependent enhancement after HIV infection}

The presence of C-ADE was studied in samples of four different seroconversion panels. MT-4 cell cultures were infected with mixtures of the virus and serum with complement added (Fig. 3). HIV antibody titres measured by the sensitive Abbott HIV 1/2 kit and the amounts of HIV antigen measured by the Abbott kit are also indicated; the extent of these parameters are given as the quotient of the sample optical density (OD) and cut-off OD. In cultures infected with virus-serum-

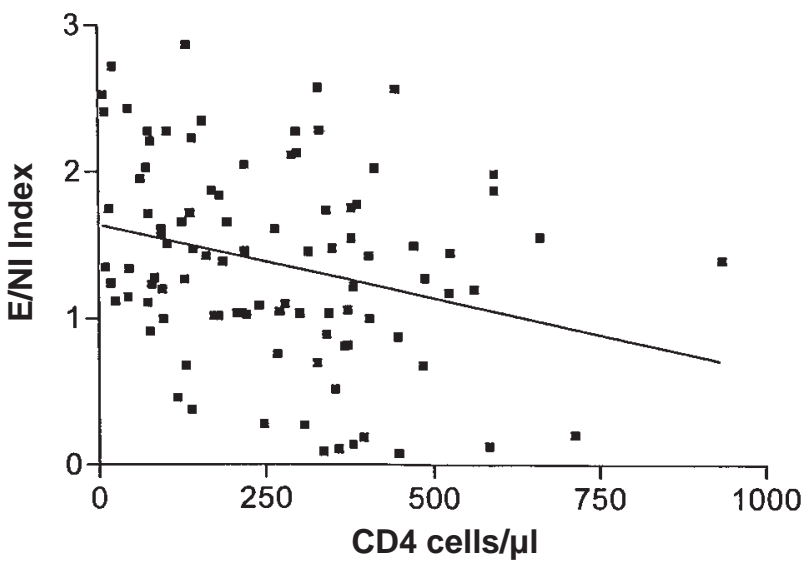

Fig. 2. Correlation of the enhancement/neutralization index $(\mathrm{E} / \mathrm{NI})$ values measured in cultures infected in the presence of complement with the CD4 cell counts in 98 HIV-infected subjects. Spearman correlation coefficient -0.279 , $P=0.0058$. 


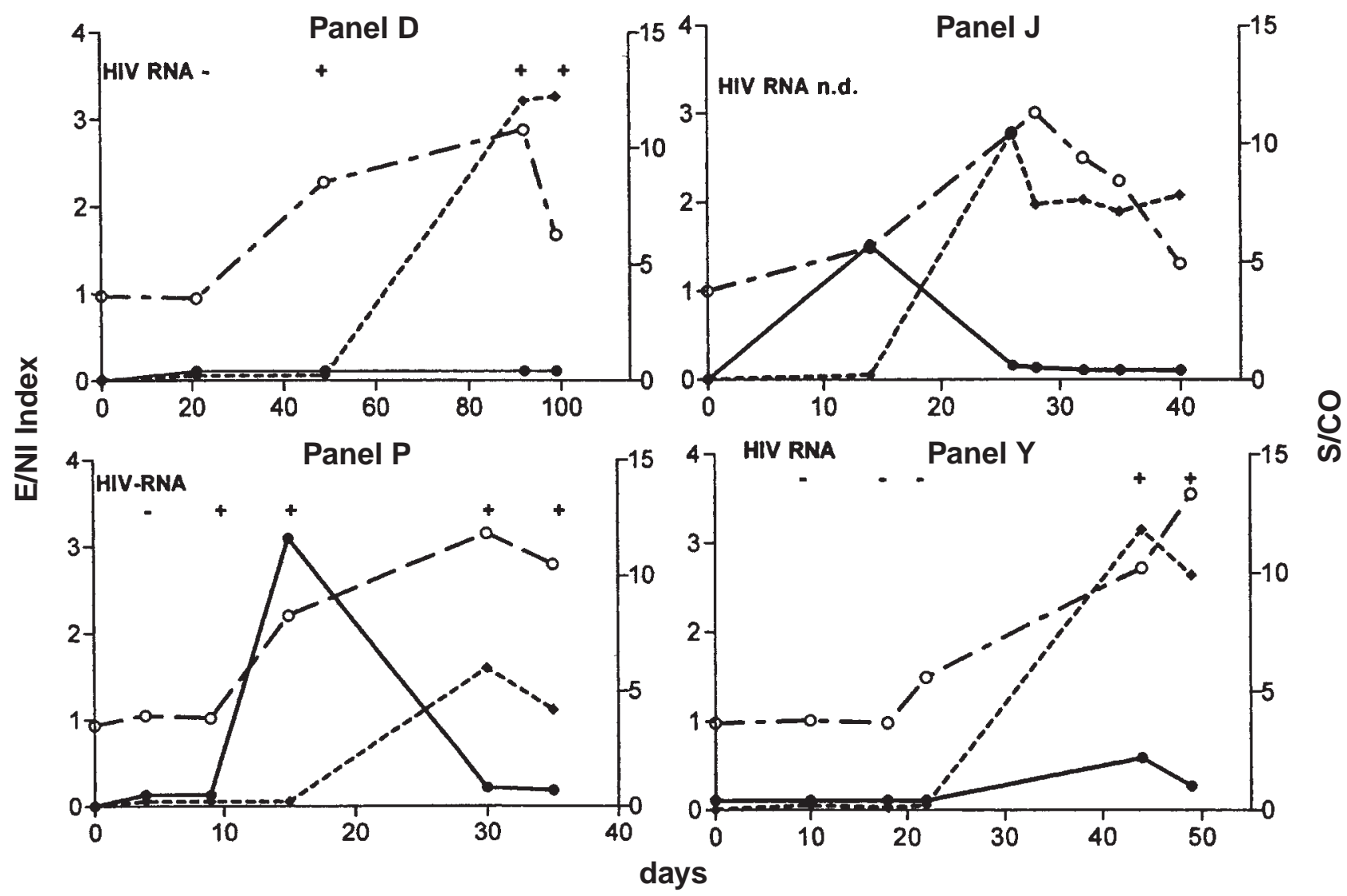

Fig. 3. Temporal changes of enhancement/neutralization index (E/NI) values, HIV-1 antigen, antibody and RNA levels in four different HIV-1 seroconversion panels. Enhancement/neutralization index values in MT-4 cell cultures infected with mixtures of HIV- $1_{\text {IIIB }} 1: 64$ dilutions of recalcified and heat-treated samples and supplemented with pooled serum from HIV-seronegative subjects as complement source $\left(\mathrm{O}_{-}{ }_{-}-{ }_{-} \mathrm{O}_{\mathrm{n}}\right.$ are shown on the left $y$-axis. HIV antibody titres measured by the Abbott HIV $1 / 2$ kit $(-----\checkmark)$, the level of p24 antigen determined by the Abbott antigen test $(-10)$ expressed in both cases in sample OD/cut-off OD (s/co) values are shown on the right $y$-axis. HIV RNA levels (+, detectable; -, undetectable; n.d., not done) are also shown. The three latter parameters were measured in the laboratory of Boston Biomedica.

complement mixtures, concomitant or just before (panels $\mathrm{D}$ and $\mathrm{P}$ ) seroconversion detected with the Abbott antibody kit, at approximately day $35-40$, a marked rise in the E/NI values was observed in all the four panels tested. Furthermore, this correlated, in general, with an increase in p24 antigenaemia and, for the three patients tested, it correlated in general with the appearance of HIV-1 RNA. (Fig. 3). By contrast, in the cultures infected with virus-serum mixtures without complement an E/NI value of 1 or less than one was observed at all time-points tested (data not shown).

\section{Increase of both complement-mediated} antibody-dependent enhancement and HIV-1 RNA during a longitudinal investigation in advanced stage HIV patients

E/NI values and HIV-1 RNA levels were longitudinally tested in 18 patients. The data obtained at the beginning and the end of the 17 month (median) observation period are shown in Fig. 4. Both the E/NI values and the viral load markedly increased during the follow-up period, and the differences between the initial and the end values were highly significant. There were no differences in the changes of either C-ADE of HIV-1 RNA values between the treated and untreated subgroups. Both parameters significantly $(P<0.05)$ increased in both groups during the observation period.

\section{Discussion}

In the present study levels of an index (E/NI) value reflecting the ratio of antibodies enhancing and neutralizing HIV-1 infection in vitro were found to be strongly associated in almost 100 patients with the plasma HIV-1 RNA levels, the best known predictor of progression of HIV-1 disease. This correlation indicates a strong association between the balance of C-ADE mediating and neutralizing antibodies on one hand and viral load on the other. 
A

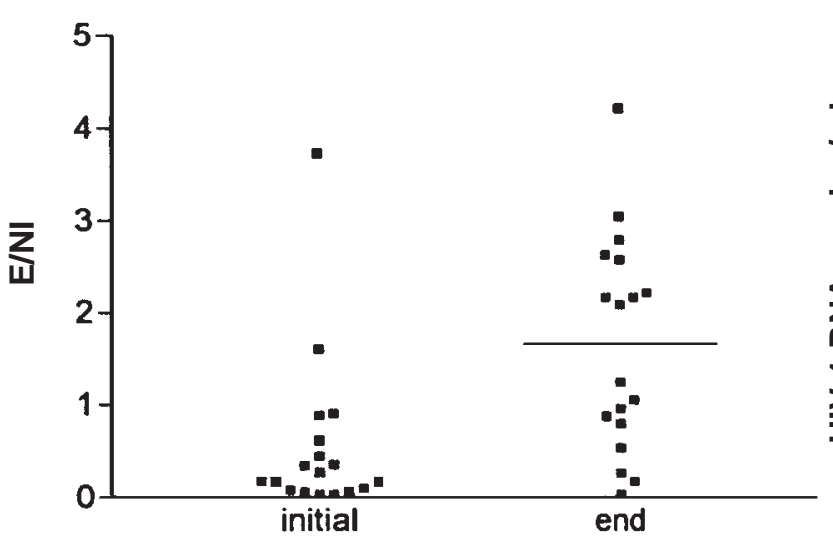

B

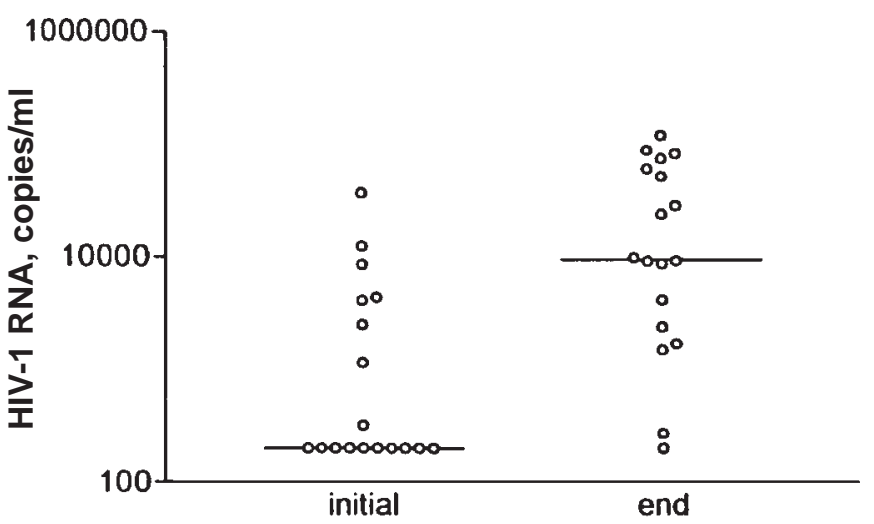

Fig. 4. Initial and end measurement in 18 HIV patients of the enhancement/neutralization index (E/NI) (A) measured in MT-4 cell cultures infected with mixtures of HIV-1 ${ }_{\text {IIIB }}, 1: 64$ dilutions of heat-treated serum samples and pooled serum from HIV-seronegative subjects as complement source and of plasma HIV-1 RNA concentrations with the Amplicor test (B) during a 17 month observation period. Significance between the two groups: for A: $P=0.0017$, for B: $P<0.0001$. Median values are indicated by horizontal lines.

The association between viral load and C-ADE can be explained in two different ways. First, it seems probable that changes in levels of HIV-1 RNA are driven by CADE activity. Sullivan et al. [31] demonstrated specific antibodies and complement fragments on virus particles isolated from the plasma of HIV-infected individuals. This observation indicates that, in vivo, complement is activated by HIV-1 in plasma, which may lead to the opsonization and lysis of the virions. On the basis of this study and our previous findings [27,29] we hypothesize that C-ADE-mediating antibodies increase the amounts of HIV-1 particles not only in vitro but also in vivo. They may inhibit complement-mediated elimination of the free virus particles or may increase virus production of the short-lived CD4 cells that produce 95-99\% of the plasma virus, or both. The hypothesis is supported by the findings of this study. If our present findings are reproducible in the early stage of HIV disease, it can be assumed that C-ADE may be one of the factors that determines the set-point of viral load and consequently the progression of HIV disease. Second, on the other hand, it cannot be excluded that the high HIV antigen load associated with the high viral burden induces increased, dose-dependent synthesis of C-ADE-mediating antibodies. However, no positive correlation between viral load and neutralizing antibodies or the total amounts of enzyme-linked immunosorbent assay (ELISA)-reactive HIV antibodies has been described so far.

We found that complement-mediated infection enhancing activity appeared early and increaseed as a function of time after HIV infection. The early appearance of C-ADE in HIV infection is in complete accordance with the findings of Montefiori et al. [32], who found C-ADE activity in the sera obtained during acute primary infection in macaques inoculated with simian immunodeficiency virus (SIV)mac251. This activity emerged before neutralizing antibodies and coincided with the initial peak and decline of plasma antigenaemia. Because the trapping of HIV on the FDC in the germinal centres of lymph nodes occurs very early after seroconversion, and the attachment of HIV immune complexes to FDC is a complementmediated process [33], it is reasonable to suppose that C-ADE-mediating antibodies present in HIV-infected persons at the same time may be one of the decisive factors of the HIV trapping in lymph nodes.

In the longitudinal study, both the E/NI values and viral load were found to increase markedly during a 1.5 year long follow-up period. In the cross-sectional study, a significant negative correlation was found between C-ADE and CD4 cell counts. E/NI values measured in the presence of complement were significantly higher in the AIDS patients than in patients in a less advanced (CDC stage III or IVA) stage of HIV disease. These observations in accordance with our previous results [29] indicate that the magnitude of enhancement measured in complement-containing serum samples from HIV-1-infected individuals correlates with immunosuppression and disease. It seems that the balance between the neutralizing and enhancing antibodies is switched towards the dominance of enhancing antibodies in the late symptomatic stage of HIV infection, and this switch may be one of the driving forces of the increase of viral load preceding clinical progression.

The main target of the C-ADE-mediating antibodies is the so-called immunodominant epitope of gp41 (see below). Therefore if the assumption on the switch in 
humoral immunity is correct, an increase in the antigp41 antibodies is expected in the late stage of HIV disease. An increase in the titres and affinity of the anti-gp41 antibodies in patients with symptomatic HIV disease compared with the asymptomatic individuals was reported by two groups $[34,35]$.

Our present novel findings, together with those reported previously by our group and others [27-29], thus indicate that C-ADE may markedly influence the natural course of HIV disease. This assumption is in disagreement with the results of Montefiori et al. [36], who did not find any correlation between C-ADEmediating antibodies and clinical progression. This discordance is most probably due to methodological differences: Montefiori et al. [36] used a much lower complement concentration, much higher input virus/cell ratio and other target cells (MT-2 versus MT-4) for culturing the virus.

The findings described in this and previous papers [27-29] were obtained in an apparently non-physiological system. The target cell, MT-4, like MT-2 used in other studies [23-25,36] is a human T cell lymphoma virus type I-infected cell-line [37] and HIV-1 ${ }_{\text {IIIB }}$ is a laboratory, $\mathrm{X} 4$ strain passaged many times through $\mathrm{T}$ cell lines. Recent studies, however, indicate that the system is much closer to the in-vivo situations than it appears to be. Nielsen et al. [38] demonstrated that CADE occurs in vitro in peripheral blood mononuclear cells, although it was not as dramatic as that detected in cell lines. The presence of CR 2 critical for C-ADE was described in $10-50 \%$ of the circulating $\mathrm{T}$ cells $[39,40]$, indicating that the use of a CR2-carrying target cell for measuring complement-related humoral factors influencing HIV growth is reasonable. Recent studies of Spear et al. [41] indicate that B cells play an important role in the enhancement of the infectivity of HIV-1 for $\mathrm{T}$ cells by antibody and complement.

An additional important question is why the measurements performed with one single $\mathrm{T}$ cell-adapted strain, HIV-1 ${ }_{\text {IIIB }}$, strongly correlates with the viral load and clinical progression of patients most probably infected with several other R5 and X4 HIV-1 strains. Recent elegant studies of Mitchell et al. [42] and earlier observations of Robinson and colleagues [43,44] help to resolve this apparent paradox. According to these investigations, the primary antigenic domains responsible for the C-ADE of HIV and SIV resides in the principal immunodominant sequence of gp41. This is a conserved sequence which, in accordance with the sitedirected mutagenesis experiments of Mitchell et al. [42], is critical for the gp120-gp41 interaction. According to their model, the binding site for enhancing antibodies on the primary association site with gp 41 is surrounded by amino-linked oligosaccharides, which are probable sites for the covalent attachment of the C3dg peptide of
C3, the physiological ligand of the CR2 receptor. The binding site for enhancing antibodies on gp41 is easily accessible after the release of gp120 from gp41 or after a conformational change in gp120 after association with CD4 cells and co-receptors [43].

In a similar way to the broadly reacting enhancing antibodies, we could also detect broadly cross-reacting neutralizing antibodies, which also seem to have prognostic significance $[7,45]$. A distinguishing feature of sera from long-term non-progressors is their higher average titre of neutralizing antibodies to HIV-1 strains IIIB and MN [46], and sera from long-term nonprogressors neutralize heterologous primary isolates more effectively than do sera from progressors [45]. The development of broadly cross-reactive neutralizing antibodies in patients might be explained by responses against highly conserved epitopes [47] or by multiple responses to isolate-specific epitopes that accumulated over time [48]. The potential benefit of antibodies that neutralize heterologous primary isolates has been described [12].

Our present observations may have two implications for HIV vaccine development. First, it seems that estimation of HIV and SIV [32] neutralization and enhancement by using complement and complementreceptor carrying target cells correlates better to the natural progression of HIV infection than any other method applied for measuring HIV humoral immunity. Therefore, it would be important to study if measurements by this or a similar procedure can be used as a correlate of HIV immune protection in animal experiments and in trials of candidate AIDS vaccines. Second, enhancing antibodies were found to develop after active and passive immunization against several virus infections, including retroviruses such as equine infectious anaemia virus [reviewed in Ref. 42]. Similar findings were obtained in SIV-immunized rhesus macaques and in volunteers vaccinated with a HIV-1 gp160 candidate vaccine [49-51]. Therefore, it is prudent to consider the potential for the development of enhancing antibodies in all vaccine preparations and trials $[24,42,52]$.

\section{Acknowledgements}

The authors would like to thank all the subjects who participated in the study. They are highly indebted to the firm Boston Biomedica for permitting the use of their data in Fig. 3, and to Marianna Lelesz for her excellent technical assistance. The authors are also most grateful to Dr Berhane Ghebrehiwet for critical reading and correcting of the manuscript. 


\section{References}

1. Mellors JW, Kingsleu LA, Rinaldo CR, Todd JA, Hoo BS, Kokka RP, Gupta P. Quantitation of HIV-1 RNA in plasma predicts outcome after seroconversion. Ann Intern Med 1995, 122:573-579.

2. Henrard DR, Phillips JF, Muenz LR, Blattner WA, Wiesner D, Eyster E, Goedert JJ. Natural history of HIV-1 cell-free viremia. JAMA 1995, 274:554-558.

3. O'Brien TR, Blattner WA, Waters D, et al. Serum HIV-1 RNA levels and time to development of AIDS in the multicenter hemophilia cohort study. JAMA 1996, 276:105-110.

4. Bruisten SM, Frissen PHJ, van Swieten P, et al. Prospective longitudinal analysis of viral load and surrogate markers in relation to clinical progression in HIV type 1 -infected persons. AIDS Res Hum Retroviruses 1997, 13:327-335.

5. Lathey JL, Hughes MD, Fiscus SA, et al. Variability and prognostic values of virologic and CD4 measures in human immunodeficeincy virus type 1-infected patients with 200-500 CD4 cells $/ \mathbf{m m}^{\mathbf{3}}$ (ACTG 175). J Infect Dis 1998, 177:614-627.

6. Quinn TC. Acute primary HIV infection. JAMA 1997, 278:58-62.

7. Connick E, Marr DG, Zhang X-Q, Clark SJ, Saag MS, Schooley RT, Curiel TJ. HIV-specific cellular and humoral immune responses in primary HIV infection. AIDS Res Hum Retroviruses 1996, 12:1129-1140.

8. Cohen OJ, Kinter A, Fauci AS. Host factors in the pathogenesis of HIV disease. Immunol Rev 1997, 159:31-48.

9. McKnight A, Clapham PR, Goudsmit J, Cheingsong-Popov R, Weber JN, Weiss RA. Development of HIV-1 group-specific neutralizing antibodies after seroconversion. AIDS 1992, 6:799-802.

10. D'Souza MP, Mathieson BJ. Early phases of HIV type 1 infection. AIDS Res Hum Retroviruses 1996, 12:1-9.

11. Legrand E, Pellegrin I, Neau D, et al. Course of specific T lymphocyte cytotoxicity, plasma and cellular viral loads, and neutralizing antibody titers in 17 recently seroconverted HIV type 1-infected patients. AIDS Res Hum Retroviruses 1997 13:1383-1394.

12. Pilgrim AK, Panteleo G, Cohen OJ, et al. Neutralizing antibody responses to human immunodeficiency type 1 in primary infection and long-term-nonprogressive infection. J Infect Dis 1997, 176:924-932.

13. Albert J, Abrahamsson B, Nagy K, Aurelius E, Gaines H, Nyström G, Fenyö EM. Rapid development of isolate-specific neutralizing antibodies after primary HIV-1 infection and consequent emergence of virus variants which resist neutralization by autologous sera. AIDS 1990, 4:107-112.

14. Lathey JL, Pratt RD, Spector SA. Appearance of autologous neutralizing antibody correlates with reduction in virus load and phenotype switch during primary infection with human immunodeficiency virus type 1. J Infect Dis 1997, 175:231-232

15. Heilman CA, Baltimore D. HIV vaccines - where are we going? Nat Med Vaccine Supplement 1998, 5:532-534.

16. Harrer T, Harrer E, Kalams SA, et al. Strong cytotoxic T cell and weak neutralizing antibody responses in a subset of persons with stable nonprogressing HIV type 1 infection. AIDS Res Hum Retroviruses 1996, 12:585-592.

17. Ogg GS, Jin X, Bonhoeffer S, et al. Quantitation of HIV 1-specific cytotoxic $T$ lymphocytes and plasma viral load of viral RNA. Science 1998, 279:2103-2106.

18. Bariou C, Genetet N, Ruffault A, Michelet C, Catier F, Genetet B. Longitudinal study of HIV-specific cytotoxic lymphocytes in HIV type 1 -infected patients: relative balance between host immune response and the spread of HIV type 1 infection. AIDS Res Hum Retroviruses 1997, 13:1301-1312.

19. Pantaleo G, Menzo S, Vaccarezza M, et al. Studies in subjects with long-term nonprogressive human immunodeficiency virus infection. N Engl J Med 1995, 332:209-216.

20. Cao Y, Qin L, Zhang L, Safrit J, Ho DD. Virologic and immunologic characterization of long-term survivors of human immunodeficiency virus type 1 infection. N Engl J Med 1995, 332:201-208.

21. Pollack H, Zhan M-X, Safrit JT, et al. CD8+ T-cell-mediated suppression of HIV replication in the first year of life: association with lower viral load and favorable early survival. AIDS 1997, 11:F9-F13.
22. Takeda A, Tuazon $\mathrm{CH}$, Ennis FA. Antibody-enhanced infection by HIV-1 via Fc receptor-mediated entry. Science 1988, 242:580-583

23. Robinson WE, Montefiori DC, Mitchell WM. A human immunodeficiency virus type 1 (HIV-1) infection-enhancing factor in seropositive sera. Biochem Biophys Res Commun 1987, 149:693-699.

24. Robinson WE, Montefiori DC, Mitchell WM. Antibody-dependent enhancement of human immunodeficiency virus type 1 infection. Lancet 1988, 1:790-794.

25. Robinson WE, Montefiori DC, Gillespie DH, Mitchell WM. Complement-mediated, antibody-dependent enhancement of HIV-1 infection in vitro is characterized by increased protein and RNA synthesis and infectious virus release. J Acquired Immune Defic Syndr 1989, 2:33-42.

26. Homsy J, Tateno M, Levy JA. Antibody-dependent enhancement of HIV infection. Lancet 1988, 1:1285-1286.

27. Tóth FD, Szabó B, Ujhelyi E, et al. Neutralizing and complement-dependent enhancing antibodies in different stages of HIV infection. AIDS 1991, 5:263-268.

28. McDougall B, Nymark MH, Landucci G, Forthal D, Robinson WE Jr. Predominance of detrimental humoral immune response to HIV-1 in AIDS patients with lymphocyte counts less than 400/ $\mathbf{m m}^{3}$. Scand J Immunol 1997, 45:103-111.

29. Füst G, Tóth FD, Kiss J, Ujhelyi E, Nagy I, Bánhegyi D. Neutralizing and enhancing antibodies measured in complement-restored serum samples from HIV-1 infected individuals correlate with immunosuppression and disease. AIDS 1994, 8:603-609.

30. Hoffman AD, Banapour B, Levy JA. Characterization of the AIDS-associated retrovirus reverse transcriptase and optimal conditions for its detection in virions. Virology 1985, 147:326-335.

31. Sullivan BL, Knopoff EJ, Saifuddin M, Takefman DM, Saarloos M$\mathrm{N}$, Sha BE, Spear GT. Susceptibility of HIV-1 plasma virus to complement-mediated lysis. Evidence for a role in clearance of virus in vivo. J Immunol 1996, 157:1791-1798.

32. Montefiori DC, Reimann KA, Letvin NL, Zhou J, Hu S-L. Studies of complement-activating antibodies in the SIV/macaque model of acute primary infection and vaccine protection. AIDS Res Hum Retroviruses 1995, 11:963-970.

33. Jolling P, Bakker LJ, van Srtijp JAG, et al. Binding of human immunodeficiency virus type-1 to follicular dendritic cells in vitro is complement dependent. J Immunol 1993, 150:1065-1073.

34. Radkowski M, Laskus I, Goch A, Slucharchyk J. Affinity of antigp41 antibody in patients infected with human immunodeficiency virus type 1. Eur I Clin Invest 1993, 23:455-458.

35. Thomas HIJ, Wilson S, O'Toole CM, Lister CM, Saeed AM Watkins RPF, Morgan-Capner P. Differential maturation of avidity of IgG antibodies to gp41, p24 and p17 following infection with HIV-1. Clin Exp Immunol 1996, 103:185-191.

36. Montefiori DC, Lefkowitz LB, Keller RE, Holmberg V, Sandtstrom E, Phair JP, and the Multicenter AIDS Cohort Study. Absence of a clinical correlation for complement-mediated, infectionenhancing antibodies in plasma and sera from HIV-infected persons. AIDS 1991, 5:513-517.

37. Harada S, Koyanagi Y, Yamamoto N. Infection of human T-lymphotropic virus type-I (HTLV-I) bearing MT-4 cells with HTLVIII (AIDS virus) chronological studies of early events. Virology 1985, 146:172-181.

38. Nielsen SD, Moller Sorensen AM, Schonning K, Lund O, Nielsen JO, Hansen JES. Complement-mediated enhancement of HIV-1 infection in peripheral blood mononuclear cells. Scand J Infect Dis 1997, 29:447-452.

39. Fischer E, Delebrias C, Kazatchkine MD. Expression of CR2 (the C3dg/EBV receptor, CD21) on normal human peripheral blood lymphocytes. J Immunol 1991, 146:865-869.

40. June RA, Landay AL, Stefanik K, Lint TF, Spear GT. Phenotypic analysis of complement receptor $2+\mathrm{T}$ lymphocytes: reduced expression by CD4+ cells in HIV-infected persons. Immunology 1992; 75:59-65.

41. Spear GT, Takefman DM, Saifuddin M, Jakubik JJ. Infectivity of HIV immune complexes after binding to B cells via CR2. Mol Immunol 1998, 35:390.

42. Mitchell WM, Ding L, Gabriel J. Inactivation of a common epitope responsible for the induction of antibody-dependent enhancement of HIV. AIDS 1998, 12:147-156. 
43. Robinson WE, Kawamura T, Lake D, Kasuho Y, Mitchell WM Hersch EM. Antibodies to the primary immunodominant virus type 1 (HIV-1) glycoprotein gp41 enhance HIV-1 infection in vitro. J Virol 1990, 64:5301-5305.

44. Robinson WE Jr, Gorny MK, Xu JY, Mitchell WM, Zolla-Pazner S. Two immunodominant domains of gp41 bind antibodies which enhance human immunodeficiency virus type $\mathbf{1}$ infection in vitro. J Virol 1991, 65:4169-4176.

45. Cao Y, Qin L, Zhang L, Safrit J, Ho DD. Virologic and immunologic characterization of long-term survivors of human immunodeficiency vírus type 1 infection. N Engl J Med 1995 332:201-208.

46. Montefiori DC, Pantaleo G, Fink LM, et al. Neutralizing and infection-enhancing antibody responses to human immunodeficiency virus type $\mathbf{1}$ in long-term non-progressors. I Infect Dis1996, 173:60-67.

47. Burton DR, Montefiori DC. The antibody response in HIV-1 infection. AIDS 1997, 11 (Suppl. A):S87-S98.
48. Wrin T, Crawford L, Sawyer L, Weber P, Sheppard HW, Hanson $\mathrm{CV}$. Neutralizing antibody responses to autologous and heterologous isolates of human immunodeficiency virus. J Acquired Immune Defic Syndr 1994, 7:211-219.

49. Gardener BM, Rosenthal A, Jennings M, Yee J, Antipa L, MacKenzie M. Passive immunization of macaques against SIV infection. J Med Primatol 1994, 23:164-174.

50. Mitchell WM, Torres J, Johnson PR, et al. Antibodies to the putative SIV infection-enhancing domain diminish beneficial effects of an SIV gp160 vaccine in rhesus macaques. AIDS 1995, 9:27-34.

51. Keefer MC, Graham BS, Belsche RB, et al. Studies of high doses of a human immunodeficiency virus type 1 recombinant glycoprotein 160 candidate vaccine in HIV type-1 seronegative humans. The AIDS Vaccine Clinical Trials Network. AIDS Res Hum Retroviruses 1994, 10:1713-1723.

52. Lévy J-P. AIDS vaccine development. Science 1998, 280:804-805. 